\title{
Active Elastic Support/Dry Friction Damper with Piezoelectric Ceramic Actuator
}

\author{
Liao Mingfu, Song Mingbo, and Wang Siji \\ School of Power and Energy, Northwestern Polytechnical University, Xian 710072, China \\ Correspondence should be addressed to Liao Mingfu; mfliao@nwpu.edu.cn
}

Received 12 September 2013; Revised 9 March 2014; Accepted 14 March 2014; Published 6 April 2014

Academic Editor: Jeong-Hoi Koo

Copyright (C) 2014 Liao Mingfu et al. This is an open access article distributed under the Creative Commons Attribution License, which permits unrestricted use, distribution, and reproduction in any medium, provided the original work is properly cited.

The basic operation principle of elastic support/dry friction damper in rotor system was introduced and the unbalance response of the rotor with elastic support/dry friction damper was analyzed theoretically. Based on the previous structure using an electromagnet as actuator, an active elastic support/dry friction damper using piezoelectric ceramic actuator was designed and its effectiveness of reducing rotor vibration when rotor traverses its critical speed and blade-out event happened was experimentally verified. The experimental results show that the active elastic support/dry friction damper with piezoelectric ceramic actuator can significantly reduce vibration in rotor system; the vibration amplitude of the rotor in critical speed region decreased more than 2 times, and the active damper can protect the rotor when a blade-out event happened, so the rotor can traverse the critical speed and shut down smoothly. In addition, the structure is much simpler than the previous, the weight was reduced by half and the power consumption was only $5 \mathrm{~W}$.

\section{Introduction}

Rotors in aircraft engines mostly operate above the first critical speed, some even over second and third critical speeds. They must traverse their critical speeds frequently in the operation. When a blade-out event happens in an engine, it must be shut down immediately [1]. However in this case, the rotor will vibrate violently while traversing the critical speed region due to the excessive unbalance. This could cause further damage to the engine [1-3]. In Certification Specifications for Large Airplanes CS-25 [4], some clauses about aircraft engine rotor are as follows. "Design precautions must be taken to minimize the hazards to the airplane in the event of an engine rotor failure." "There must be means for stopping the rotation of any engine individually in flight." This is a crucial challenge to the design of aircraft engines.

In order to deal with abovementioned problems, effective damping must be incorporated into rotor systems. It has been proven theoretically and experimentally that as a new rotor vibration damper, the elastic support/dry friction damper can significantly attenuate the vibration amplitude of rotor system in the critical speed region [5-7]; moreover, it is convenient to be controlled by adjusting control voltage [8-11]. However, due to its oversized electromagnetic actuator, the application of such a damper in aircraft engines will be restricted.

In recent years, smart materials have received more and more attention in structure vibration control. It has brought some new ideas for vibration reduction design of mechanical structure [12-14]. In this paper, an active elastic support/dry friction damper with piezoelectric ceramic actuator was designed, and an experimental investigation on the damper controlling the rotor vibration in a blade-out event has been carried out. The result shows that the vibration of rotor system in the critical speed region can be effectively controlled when a blade-out event takes place, so the rotor can be shut down smoothly. In addition, due to its simple structure, light weight, fast response, and low power consumption, this new damper with piezoelectric ceramic actuator shows a promising application prospect.

\section{Basic Operation Principle of Elastic Support/Dry Friction Damper}

The basic operation mode of an elastic support/dry friction damper [7] is shown in Figure 1. A rotor (4) is supported by 


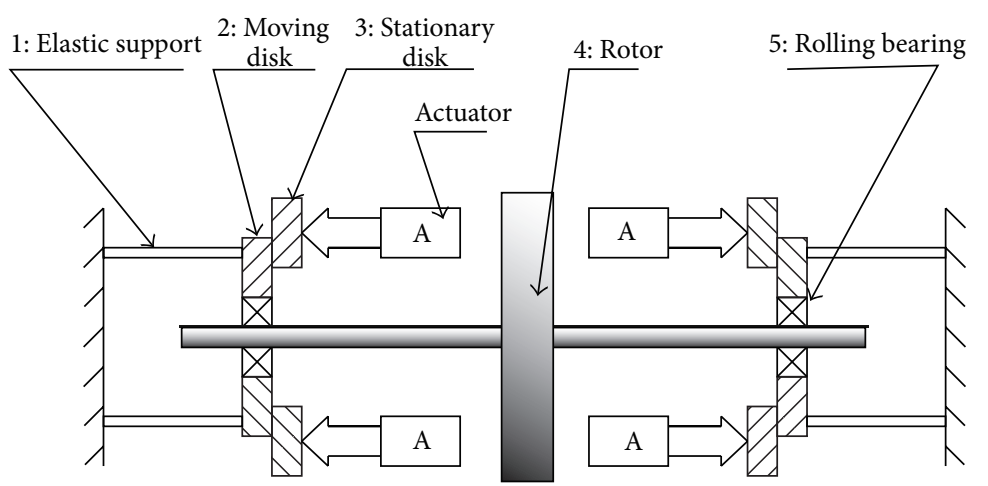

FIGURE 1: The basic operation principle of elastic support/dry friction damper (1: elastic support, 2: moving disk, 3: stationary disk, 4: rotor, and 5: rolling bearing, A: actuator).

two elastic supports (1) and at the end cross section of each one the dry friction damper can be fixed. The damper consists of 3 key components: moving disk (2), stationary disk (3), and actuator (A). The moving disk which is fixed at the end cross section of the elastic support is connected with bearing outer ring and it does not rotate with the rotor. The stationary disk is fixed on casing and can be moved in axial direction.

If the moving disk moves with the rotor vibration, a relative motion and frictional force between the moving disk and the stationary disk will take place. The frictional force can be changed through adjusting pressing force by the actuator. When the actuator provides an appropriate pressing force, this will lead to a dry friction damping dissipating the vibration energy.

\section{Unbalance Response of the Rotor with Elastic Support/Dry Friction Damper}

In order to explain the principle and mechanism of the elastic support/dry friction damper, the rotor system has been considered as a rigid rotor supported on elastic supports, as shown in Figure 2. It consists of a concentrated mass, a spring, a viscous damper, and a dry friction damper. The concentrated mass $M$ includes all the system mass, $k_{1}$ is the stiffness coefficient of the elastic support, and $c$ is the damping coefficient of the system without the damping from the dry friction damper. In the dashed box, it is the dry friction damper. $z(t)$ represents the damping force from the damper, $z_{s}=\mu N$ is the friction force, and $N$ is the pressing force between the moving disk and stationary disk. When a relative motion between the moving disk and stationary disk occurs, $z_{s}=\mu N$ and when the relative motion does not occur, the static contact of both disks is represented by a stiffness coefficient $k_{2}$.

The constitutive relation of the damping force $z(t)$ from the dry friction damper is shown in Figure 3. The $x_{m}$ represents the amplitude of the displacement of mass $M$. This reveals the hysteretic property of $z(t)$ related to the displacement $x$ between the two disks. The following analysis is based on harmonic balance method $[15,16]$. limit is

The maximum deformation overcoming the static contact

$$
x_{y}=\frac{z_{s}}{k_{2}} .
$$

It means when $x_{m}>x_{y}$, there will be a relative motion between the two disks and when $x_{m}<x_{y}$, there will be no relative motion between both disks.

In the case of $x_{m}>x_{y}$, the equation of motion of the rotor system is

$$
M \ddot{x}+c \dot{x}+k_{1} x+z(t)=m \varepsilon \Omega^{2} \sin \Omega t,
$$

where $m$ is the unbalanced mass and $\varepsilon$ is the eccentricity of the mass $m$.

We introduce the following variables:

$$
\begin{gathered}
F=m \varepsilon, \\
\omega^{2}=\frac{k_{1}}{M}, \\
D=\frac{c}{2 \sqrt{M k_{1}}}, \\
G=\frac{F}{M},
\end{gathered}
$$

where $F$ represents the unbalance of the rotor; $D$ is defined as damping ratio; $G$ is defined as the relative eccentricity.

Instituting them into (2) gives

$$
\ddot{x}+2 D \omega \dot{x}+\omega^{2} x+\frac{z(t)}{M}=G \Omega^{2} \sin (\Omega t) .
$$

It is a nonlinear equation associated with friction models. Generally, one cannot obtain an analytical solution directly. However, according to references $[15,16]$, the synchronous component dominates in the vibration of mechanical systems in some cases of hysteretic friction modes. Therefore, we assume the solution of (4) as the following form approximately:

$$
x(t)=x_{m} \sin (\Omega t+\varphi) .
$$




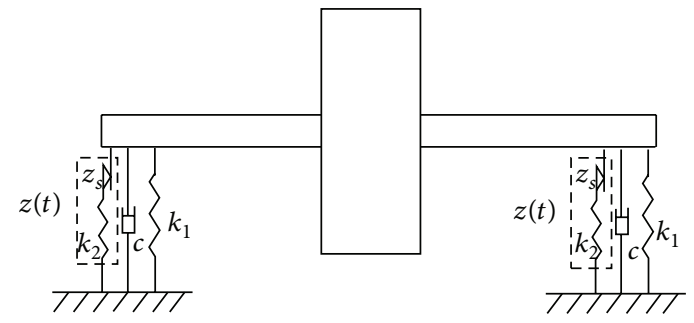

(a)

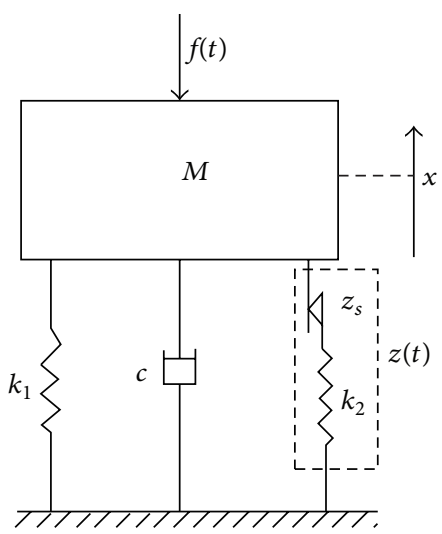

(b)

FIGURE 2: The one degree of freedom model of the rotor system with dry friction damper.

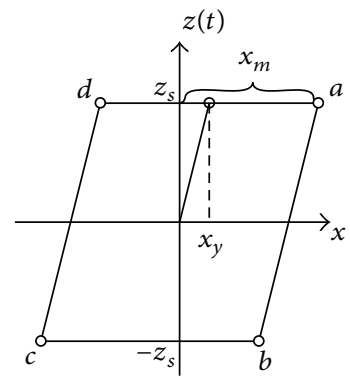

FIgURE 3: The constitutive relation of the damping force $z(t)$.

The damping force $z(t)$ is a periodic function with the rotation of the rotor, its period is $2 \pi / \Omega$.

Let

$$
\Omega t+\varphi=\theta(t)+\frac{\pi}{2}
$$

and substitute it into (5), we obtain

$$
x(\theta)=x_{m} \cos (\theta) .
$$

Then, according to the relationship between $z(\theta)$ and $x(\theta)$ in Figure $4, z(\theta)$ at any $\theta$ can be obtained as follows: $z(\theta)$

$$
= \begin{cases}z_{s}\left[\frac{x_{m} \cos \theta-\left(x_{m}-x_{y}\right)}{x_{y}}\right] & 0 \leq \theta<\bar{\theta} \\ -z_{s} & \bar{\theta} \leq \theta<\pi \\ -z_{s}\left[\frac{x_{m} \cos (\theta-\pi)-\left(x_{m}-x_{y}\right)}{x_{y}}\right] & \pi \leq \theta<\bar{\theta}+\pi \\ z_{s} & \bar{\theta}+\pi \leq \theta<2 \pi,\end{cases}
$$

where $\bar{\theta}$ is the phase angle of point $b$ and can be calculated by the following equation:

$$
\bar{\theta}=\arccos \frac{x_{m}-2 x_{y}}{x_{m}} .
$$

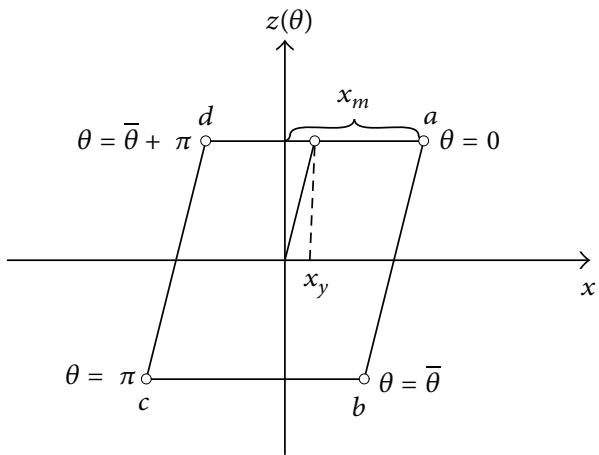

FIGURE 4: The constitutive relation of the damping force $z(\theta)$ (angle domain).

Make Fourier series expansion for (8):

$$
z(\theta)=\sum\left(a_{n} \cos n \theta+b_{n} \sin n \theta\right) .
$$

In the critical region, the synchronous component dominates in the vibration of mechanical systems in some cases of hysteretic friction modes $[15,16]$. So let $n=1, z(\theta)$ can be simplified approximately as

$$
z(\theta)=a_{1} \cos \theta+b_{1} \sin \theta,
$$

where

$$
\begin{aligned}
& a_{1}=\frac{1}{\pi} \int_{-\pi}^{\pi} z(\theta) \cos \theta d \theta \\
& b_{1}=\frac{1}{\pi} \int_{-\pi}^{\pi} z(\theta) \sin \theta d \theta .
\end{aligned}
$$

Substituting (8) into (12), $a_{1}$ and $b_{1}$ are then obtained as follows:

$$
\begin{gathered}
a_{1}=\frac{z_{s}}{\pi}(\bar{\theta}-\sin \bar{\theta} \cos \bar{\theta}) \frac{x_{m}}{x_{y}} \\
b_{1}=-\frac{4 z_{s}}{\pi}\left(1-\frac{x_{y}}{x_{m}}\right) .
\end{gathered}
$$




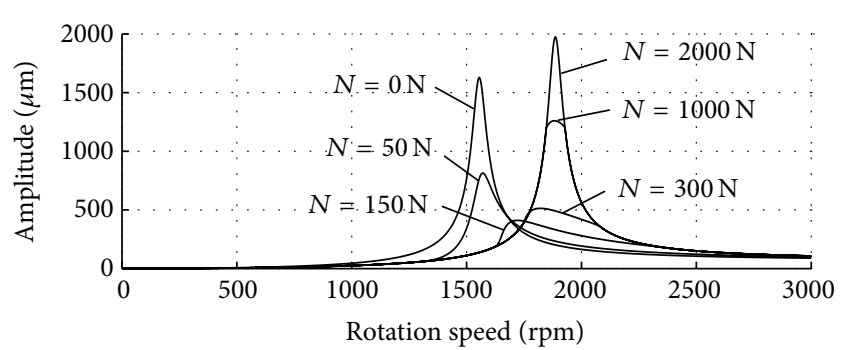

FIgURE 5: The amplitude-frequency diagram of the rotor under different pressing forces.

Substitute $a_{1}$ and $b_{1}$ into (11) and considering (6), we get

$$
\begin{gathered}
z(t)=\frac{z_{s}}{\pi}(\bar{\theta}-\sin \bar{\theta} \cos \bar{\theta}) \frac{x_{m}}{x_{y}} \sin (\Omega t+\varphi) \\
+\frac{4 z_{s}}{\pi}\left(1-\frac{x_{y}}{x_{m}}\right) \cos (\Omega t+\varphi) .
\end{gathered}
$$

By substitution of $z(t)$, (4) becomes

$$
\begin{gathered}
\ddot{x}+2 D \omega \dot{x}+\omega^{2} x+\frac{z_{s}}{\pi M}(\bar{\theta}-\sin \bar{\theta} \cos \bar{\theta}) \frac{x_{m}}{x_{y}} \sin (\Omega t+\varphi) \\
+\frac{4 z_{s}}{\pi M}\left(1-\frac{x_{y}}{x_{m}}\right) \cos (\Omega t+\varphi)=G \Omega^{2} \sin (\Omega t) .
\end{gathered}
$$

Substituting (5) into (15) and equating the coefficients of $\cos (\Omega t+\varphi)$ and $\sin (\Omega t+\varphi)$ from both sides of the equation, respectively, a system of algebraic equations is then obtained as follows:

$$
\begin{gathered}
-x_{m} \Omega^{2}+\omega^{2} x_{m}+\frac{1}{M} \frac{z_{s}}{\pi}(\bar{\theta}-\sin \bar{\theta} \cos \bar{\theta}) \frac{x_{m}}{x_{y}}=G \Omega^{2} \cos (\varphi) \\
2 D \omega x_{m} \Omega+\frac{1}{M} \frac{4 z_{s}}{\pi}\left(1-\frac{x_{y}}{x_{m}}\right)=-G \Omega^{2} \sin (\varphi) .
\end{gathered}
$$

Getting square of both sides of the above two equations and adding them together, we obtain

$$
\begin{aligned}
& {\left[\left(\omega^{2}-\Omega^{2}\right) x_{m}+\frac{\omega^{2} k_{2} x_{m}}{k_{1} \pi}(\bar{\theta}-\sin \bar{\theta} \cos \bar{\theta})\right]^{2}} \\
& +\left[2 D \omega \Omega x_{m}+\frac{4 \omega^{2} \mu N}{k_{1} \pi}\left(1-\frac{\mu N}{k_{2} x_{m}}\right)\right]^{2}=G^{2} \Omega^{4},
\end{aligned}
$$

where $\omega^{2}=k_{1} / M, k_{2}=z_{s} / x_{y}, z_{s}=\mu N$.

Equation (17) holds only when $x_{m}>x_{y}$.

In the case of $x_{m}<x_{y}$, there is no relative motion between the moving disk and stationary disk. Thus, the system is purely linear, and the unbalance response $x_{m}$ of the rotor can be calculated by (18) directly:

$$
x_{m}=\frac{G \Omega^{2}}{\sqrt{\left(\omega^{2}-\Omega^{2}\right)^{2}+(2 \omega D \Omega)^{2}}},
$$

where $\omega^{2}=K / M, D=c / 2 \sqrt{M K}, K=k_{1}+k_{2}$.

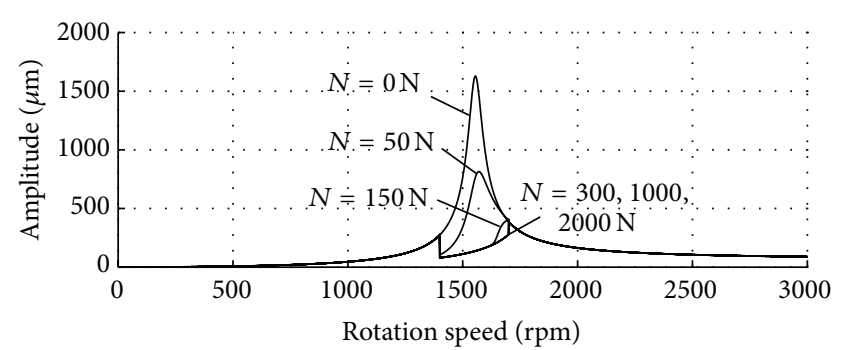

FIGURE 6: The amplitude-frequency diagram of the rotor under different pressing forces applied during the critical speed region (1400 1700 rpm).

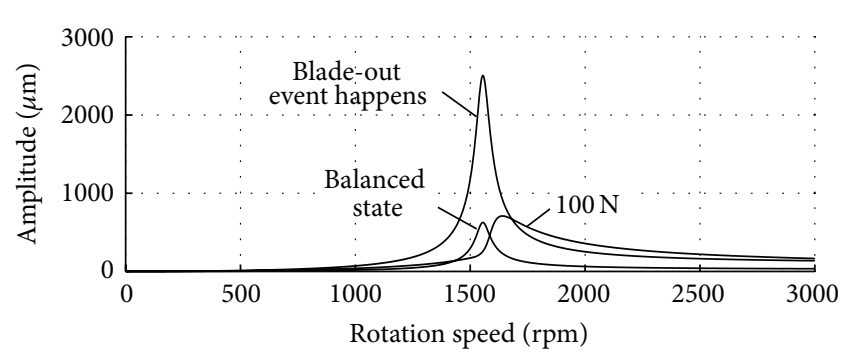

FIGURE 7: The amplitude-frequency diagram of the rotor when blade-out event happened.

Figure 5 shows the comparison of the unbalance response under different pressing forces between the moving disk and stationary disk by digital simulation. The parameters are as follows:

$$
\begin{gathered}
M=20 \mathrm{~kg}, \quad k_{1}=5.3 \times 10^{5} \mathrm{~N} / \mathrm{m}, \\
k_{2}=2.5 \times 10^{5} \mathrm{~N} / \mathrm{m}, \quad c=130 \mathrm{~N} \cdot \mathrm{s} / \mathrm{m}, \\
F=1.3 \times 10^{-3} \mathrm{~kg} \cdot \mathrm{m}, \quad \mu=0.3, \\
N=0,50,150,300,1000,2000 \mathrm{~N} .
\end{gathered}
$$

As shown in Figure 5, with the increase of the pressing force $N$, the peak amplitude of the rotor at the critical speed decreases at first and then increases. So, there must be an optimum pressing force under which the rotor can traverse the critical speed smoothly. When the pressing force increases to $2000 \mathrm{~N}$, the equation $x_{m}<x_{y}$ is always true in the whole rotational speed region. There is no relative motion between the moving disk and stationary disk. Under this condition, the elastic support/dry friction damper will not come into play.

Furthermore, from Figure 5, we can also see that the critical speed of the rotor increases with the pressing force $N$. This is due to the stiffness increase by $k_{2}$ which is brought by the damper. And this problem can be avoided by changing the control strategy of the pressing force. Figure 6 is the amplitude-frequency diagram under different pressing forces only applied during the critical speed region (1400-1700 rpm) with other parameters unchanging.

As shown in Figure 6, when pressing force is only applied in the critical speed region $(1400-1700 \mathrm{rpm})$, the elastic 


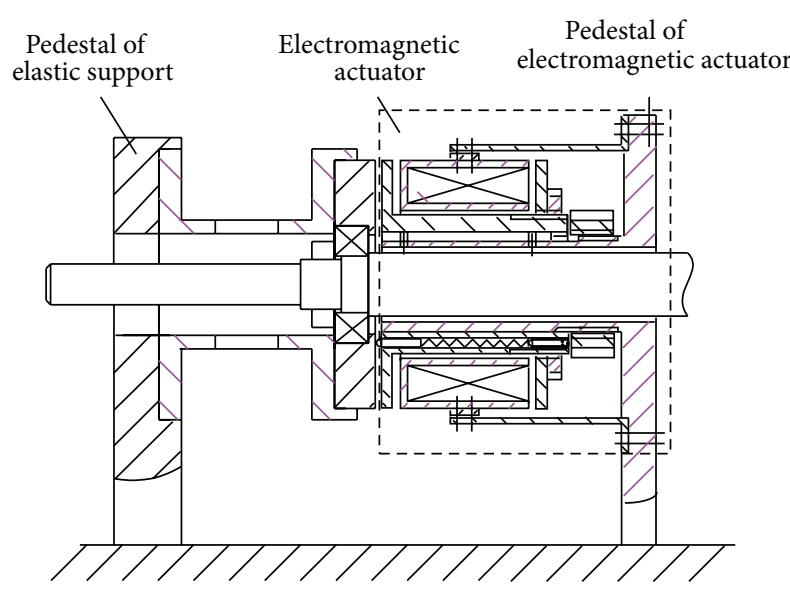

(a)

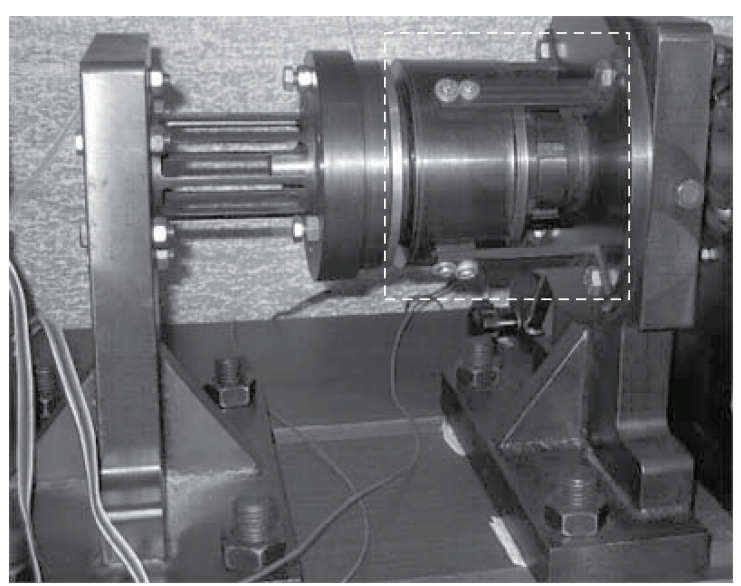

(b)

FIGURE 8: The active elastic support/dry friction damper with electromagnetic actuator.

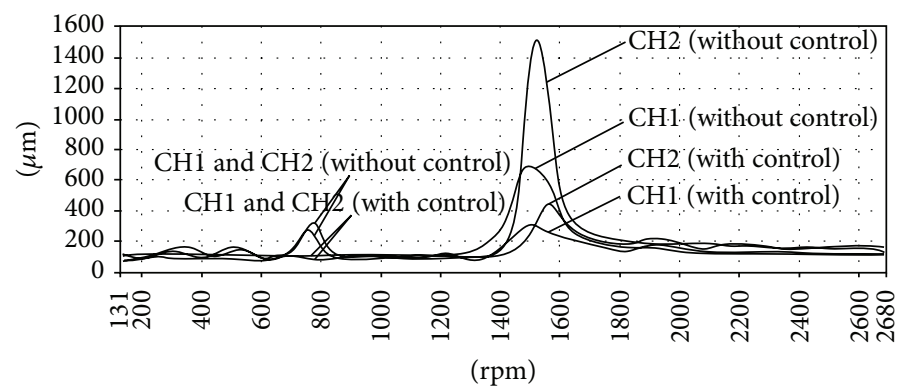

(a) The Bode curves

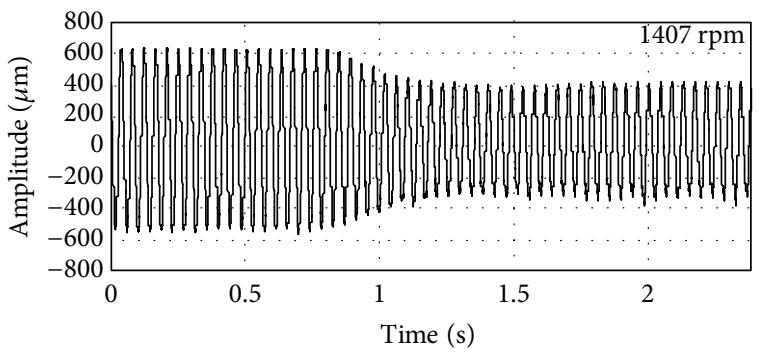

(b) The time domain waveforms

FIGURE 9: The Experimental result of the rotor with active elastic support/dry friction damper with electromagnetic actuator.

support/dry friction damper can reduce the peak amplitude of the rotor vibration at the critical speed significantly, while the dynamic characteristics beyond the critical speed region will not change, despite of the pressing force input, as shown in Figure 6.

Assume that the original unbalance force of the rotor is $F=0.5 \times 10^{-3} \mathrm{~kg} \cdot \mathrm{m}$, the rotational speed of the rotor is $2800 \mathrm{rpm}$ (above the critical speed) and keeps other parameters unchanging. When blade-out event happens, the unbalance force of the rotor increases to $F=2 \times 10^{-3} \mathrm{~kg}$. $\mathrm{m}$. It causes a sudden increase of vibration of the rotor. The vibration will become violent when the rotor passes the critical speed. This violent vibration may lead to damage to a machine in practice. Figure 7 shows the amplitude-frequency diagram of the rotor when blade-out event happened.

As shown in Figure 7, the amplitude of the rotor at the critical speed increases 3 4 times when blade-out event happened. If there are no effective damping measures in the rotor system, some serious damages may be caused during the coast down process. When an appropriate dry friction damping force is added (the pressing force was $100 \mathrm{~N}$ ), the amplitude of vibration at the critical speed will be attenuated significantly and the rotor may be protected in this case.

\section{Structure of the Piezoelectric Ceramic Actuator and the Experimental Setup}

The structure of the active elastic support/dry friction damper with electromagnetic actuator is shown in Figure 8. The device in the dashed box of the figure is the electromagnetic actuator. Theoretical and experimental investigations have proven that such a type of active dampers is very effective for reducing vibrations of rotor systems [8-11]. Figure 9 shows experimental results of a rotor with active elastic support/dry friction damper with electromagnetic actuator $[8,10]$. The amplitude of vibration of the rotor is significantly attenuated at critical speed by the damper. But for application in aircraft engines, its size and weight must be reduced; besides, it is too complicated.

To this end, an active elastic support/dry friction damper with piezoelectric ceramic actuator was designed. The stiffness of the piezoelectric ceramic used is $35 \mathrm{~N} / \mu \mathrm{m}$. As shown in Figure 10, the piezoelectric ceramic can elongate at least $37 \mu \mathrm{m}$ in the range of operating voltage, or create a maximum extrusion force of about $1300 \mathrm{~N}$. It is adequate to provide the pressing force for the damper.

The basic structure of the piezoelectric ceramic actuator is shown in Figure 11. The component (1) is the stationary disk, 


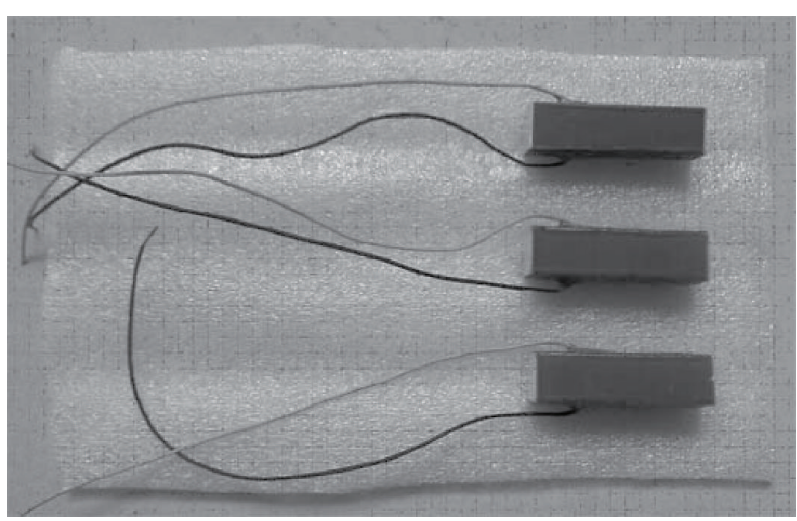

(a)

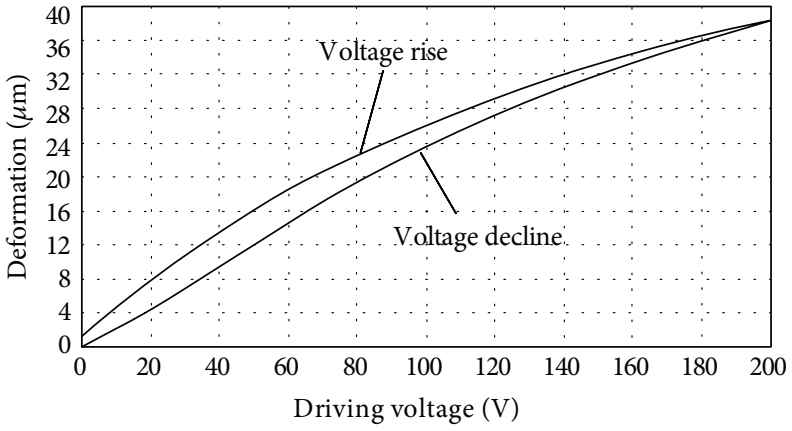

(b)

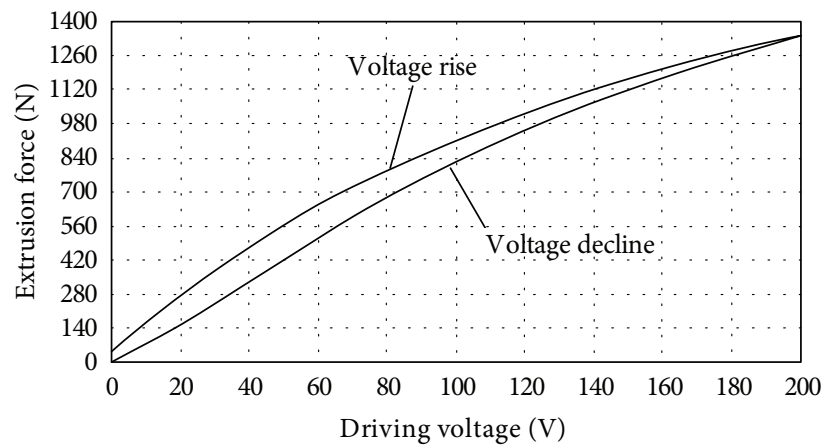

(c)

FIGURE 10: The piezoelectric ceramic and its voltage-strain curves and voltage-force curves.

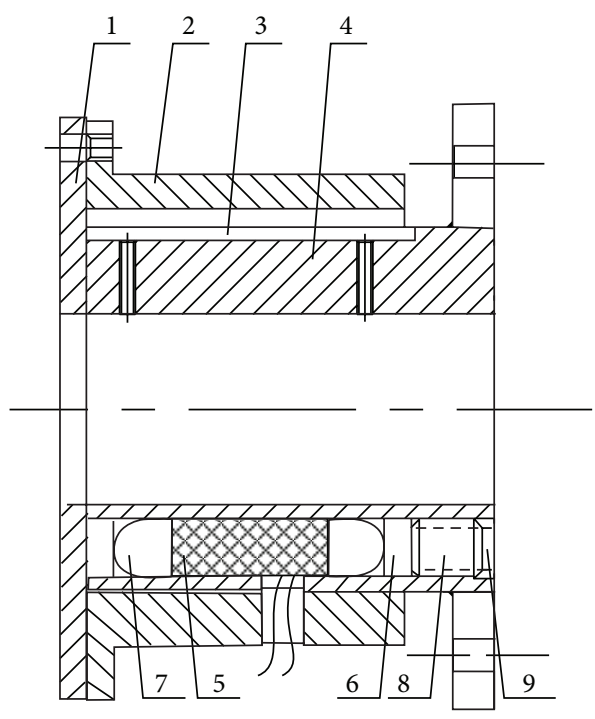

(a)

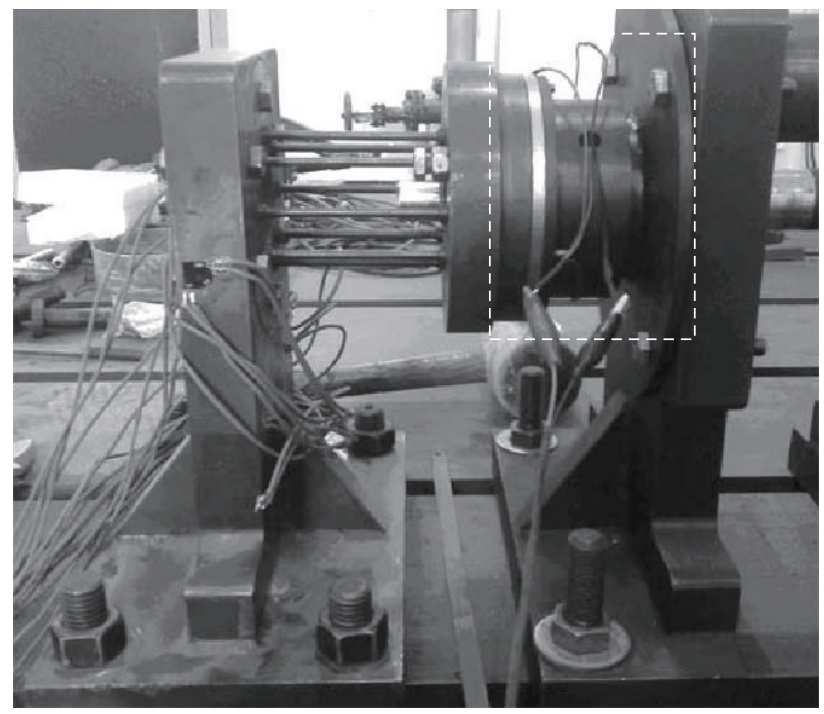

(b)

FIGURE 11: The elastic support/dry friction damper with piezoelectric ceramic actuator (1: stationary disk, 2: sleeve, 3: diving key, 4: support cylinder, 5: piezoelectric ceramic, 6: small disc, 7: hemisphere, 8: preload bolt, and 9: preload bolt hole). 


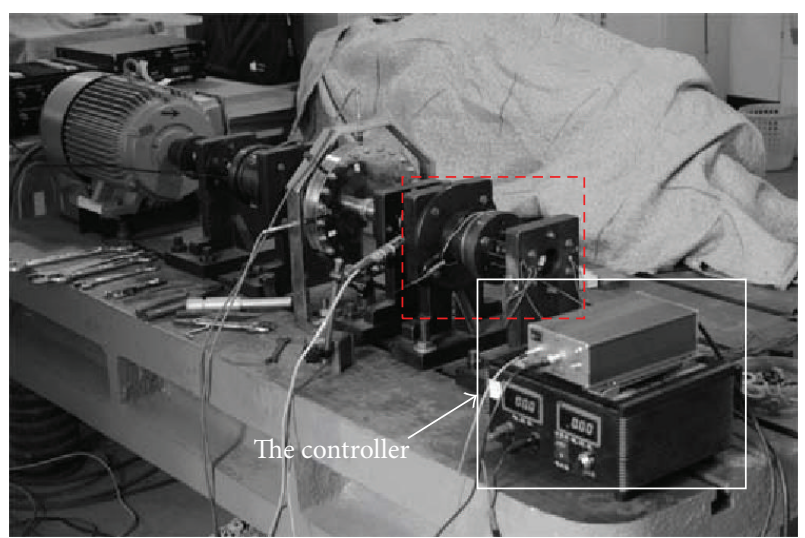

FIGURE 12: The whole experimental setup.

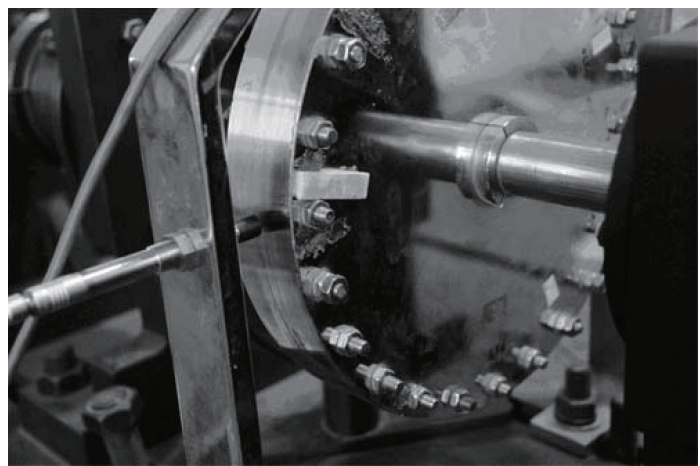

Figure 13: Simulation of blade-out event.

which is fixed on sleeve (2). The sleeve which is mounted on support cylinder (4) can move in axial direction. Diving key (3) can prevent the sleeve from rotating. Piezoelectric ceramic (5) are placed in three via holes which are bored in support cylinder (4). As the piezoelectric ceramic cannot bear shear load, a small disc (6) and a hemisphere (7) are placed before and behind the piezoelectric ceramic, respectively. The preload between the stationary disk and moving disk can be adjusted by screwing preload bolt (8) in preload bolt hole (9). Then, the pressing force between the stationary disk and moving disk can be changed by adjusting the control voltage of the piezoelectric ceramic. This means that the damping of the rotor system can be controlled by adjusting the voltage.

The whole experimental setup is shown in Figure 12. It mainly includes a rotor, two elastic support/dry friction dampers, a photoelectric probe (Schenck P84), and two proximity probes (Schenck IN-085). The probe information is shown in the following Table 1. The signals of the probes are acquired and processed by a condition monitoring and dynamic balancing system (CAMB9100).

As a result of using the piezoelectric ceramic, the structure of the active elastic support/dry friction damper is much simpler and lighter (its weight is $3.5 \mathrm{~kg}$ ) than the previous electromagnetic actuator (its weight is $7.4 \mathrm{~kg}$ ).

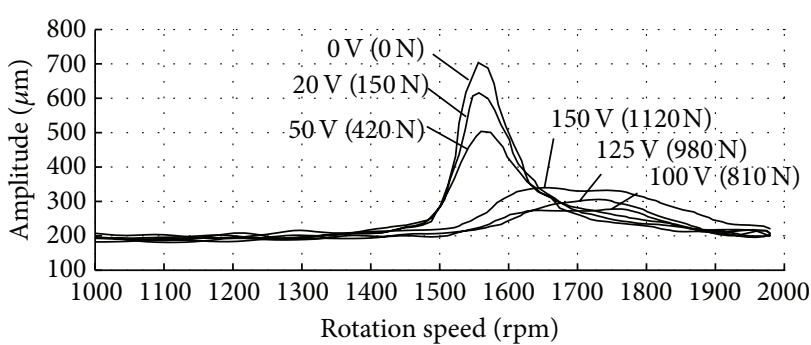

FIGURE 14: The Bode curves of the rotor system with various damping force applied from the beginning to the end of the rotor running $(\mathrm{CH} 1)$.

TABLE 1: Probe information.

\begin{tabular}{lccc}
\hline Channels & Probe type & Positions & Angles \\
\hline Rotation speed & $\begin{array}{c}\text { photoelectric } \\
\text { probe }\end{array}$ & Near the shaft & $\begin{array}{c}\text { Horizontal } \\
\left(15^{\circ}\right)\end{array}$ \\
CH1 & Proximity probe & Probe frame & $\begin{array}{c}\text { Horizontal } \\
\left(0^{\circ}\right)\end{array}$ \\
$\mathrm{CH} 2$ & Proximity probe & Probe frame & Vertical $\left(90^{\circ}\right)$ \\
\hline
\end{tabular}

\section{Experimental Process and Analyses}

In order to verify the damping effect of the active elastic support/dry friction damper with piezoelectric ceramic actuator and its protection for the rotor when blade-out event happens, the following two sets of experiments were carried out.

(A) The damping effect of the active elastic support/dry friction damper with piezoelectric ceramic actuator is as follows.

(1) The rotor was shut down and coasted down from $2000 \mathrm{r} / \mathrm{min}$ to $0 \mathrm{r} / \mathrm{min}$, and the dry friction damper was actuated from beginning to the end of the rotor running. The control voltage of the piezoelectric ceramic actuator was adjusted as $0 \mathrm{~V}, 20 \mathrm{~V}, 50 \mathrm{~V}, 100 \mathrm{~V}$, $125 \mathrm{~V}$, and $150 \mathrm{~V}$ (the pressing force was $0 \mathrm{~N}, 150 \mathrm{~N}$, $420 \mathrm{~N}, 810 \mathrm{~N}, 980 \mathrm{~N}$, and $1120 \mathrm{~N})$, respectively.

(2) The rotor was shut down and coasted down from $2000 \mathrm{r} / \mathrm{min}$ to $0 \mathrm{r} / \mathrm{min}$, and the dry friction damper was actuated just in the critical speed region $(1400 \mathrm{rpm} \sim 1670 \mathrm{rpm})$. The same control voltages were input into the piezoelectric ceramic actuator, that is, $0 \mathrm{~V}, 100 \mathrm{~V}, 125 \mathrm{~V}$, and $150 \mathrm{~V}$ (the pressing force was $0 \mathrm{~N}, 810 \mathrm{~N}, 980 \mathrm{~N}$, and $1120 \mathrm{~N}$ ).

(3) The rotor was run at a given rotational speed (1524 rpm) near the critical speed and afterwards the dry friction damper was actuated on the rotor.

(B) The rotor protection by active elastic support/dry friction damper with piezoelectric ceramic actuator when blade-out event happens is as follows.

(1) The rotor was run at a given speed (1700 rpm) above the critical speed. Then, the blade-out event happened and afterwards the dry friction damper was actuated. 


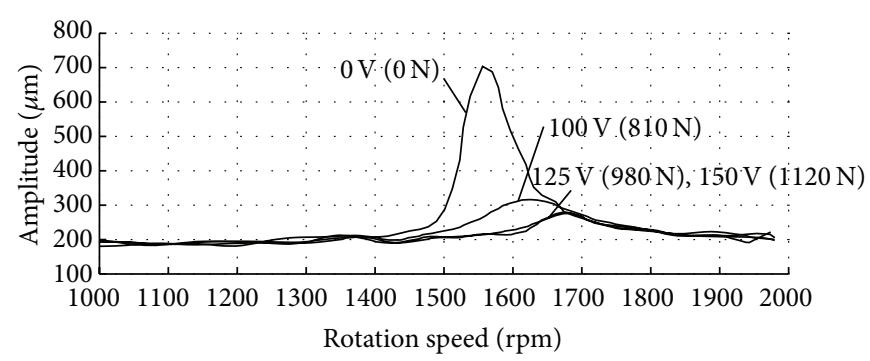

(a)

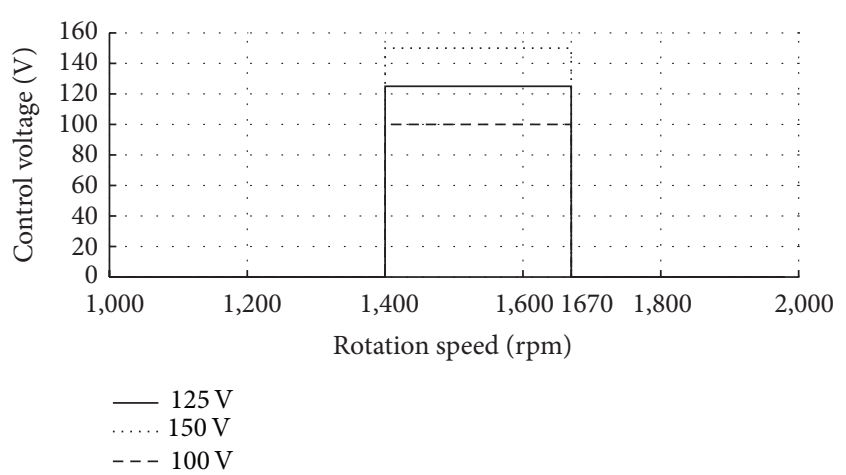

(b)

FIGURE 15: The Bode curves of the rotor system with various damping force applied just during the critical speed region (1400 rpm 1670 rpm) $(\mathrm{CH} 1)$.

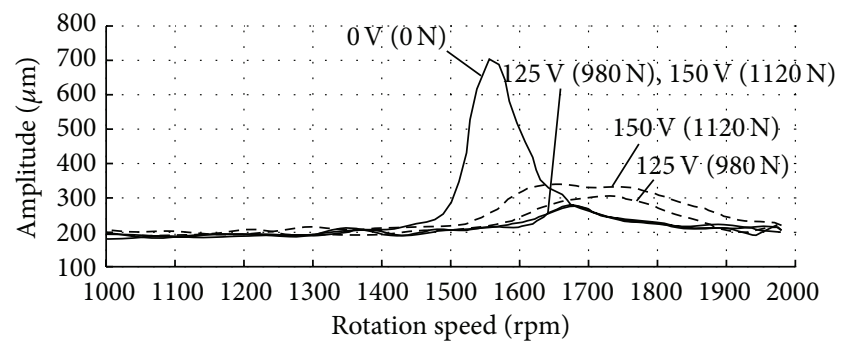

Figure 16: The contrast of Bode curves of the rotor system by two damping applied methods $(\mathrm{CH} 1)$.

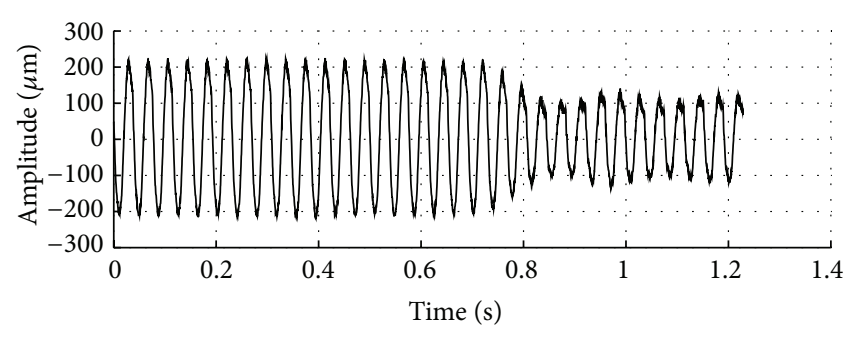

FIGURE 17: The time domain waveforms of the rotor system at the rotational speeds of $1524 \mathrm{rpm}$.

(2) The rotor was run up under well balanced state to a given speed $(1700 \mathrm{rpm})$ above the critical speed, and then the blade out event happened. Afterwards the rotor was shut down and coasted down without dry friction damper applied. Finally, this process was repeated with dry friction damper applied.

As shown in Figure 13, a mass of 1.5 gram was adhered on the rotor and flew out at about $1700 \mathrm{rpm}$. This was used to simulate the blade-out event.

Figure 14 shows the result of experiment A(1). It is the amplitude of rotor vibration in horizontal direction versus rotational speed; the voltage input into the damper is taken as parameter affecting the pressing force between the stationary disk and moving disk. In vertical direction, it follows the same trend. When the elastic support/dry friction damper

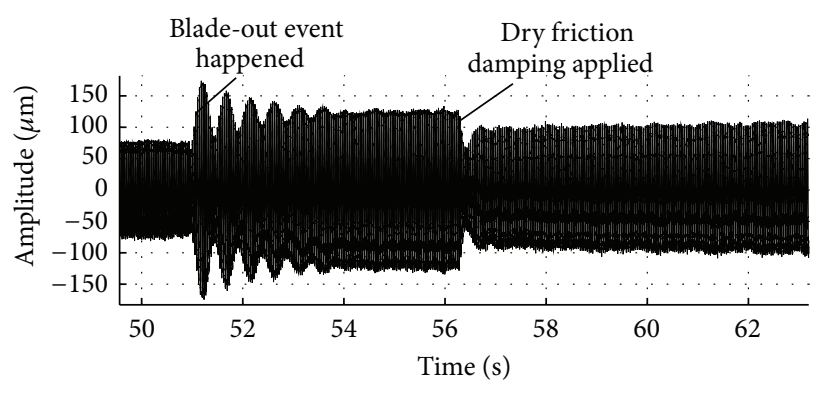

FIGURE 18: The rotor protection by elastic support/dry friction damper when blade-out event happened.

was actuated, the vibration amplitude of the rotor system decreased significantly, especially in the critical speed region. The attenuation of the rotor vibration by the damper was sensitively related to the control voltage provided to the damper. There was an optimum control voltage $(100 \mathrm{~V}$, the pressing force was $810 \mathrm{~N}$ ) suppressing the amplitude by 2.6 times, that is, from $700 \mu \mathrm{m}$ to $270 \mu \mathrm{m}$. Beyond this optimum voltage, the vibration amplitude in the critical speed region increased slightly. Additionally, the critical speed of the rotor increased slightly too. This result agrees well with the theoretical analysis in Section 2.

Figure 15 illustrates the result of experiment $\mathrm{A}(2)$. It indicates the effect of the damper by on/off control strategy in the critical speed region (1400 rpm 1670 rpm). Figure 15(a) shows the amplitude of rotor vibration in horizontal direction versus rotational speed; the voltage input into the damper is taken as parameter affecting the pressing force between the stationary disk and moving disk. In vertical direction, it follows the same trend. Figure 15(b) shows the damper's control voltage versus the rotational speed. It was input into the damper only in the critical speed region and followed on/off control strategy. In Figure 15(a), when the elastic support/dry friction damper was actuated only in the critical speed region, the vibration amplitude of the rotor system in the region was significantly reduced, while in the other region it did not change. When the control voltage reached $125 \mathrm{~V}$ (the 


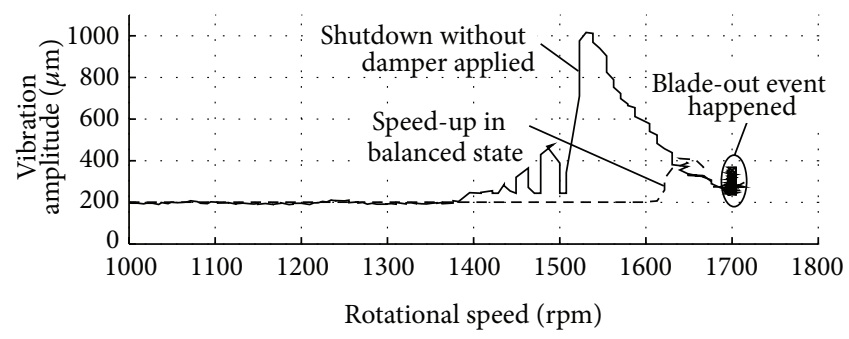

(a) The rotor was shut down without dry friction damper applied

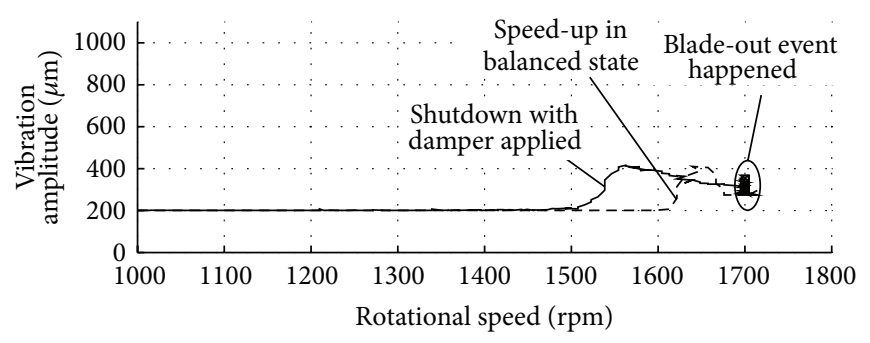

(b) The rotor was shut down with dry friction damper applied

FIGURE 19: The rotor protection by elastic support/dry friction damper during shutdown.

pressing force was $980 \mathrm{~N}$ ), the amplitude at the critical speed was also decreased 2.6 times. When the control voltage was $125 \mathrm{~V}$ (the pressing force was $980 \mathrm{~N}$ ) and $150 \mathrm{~V}$ (the pressing force was $1120 \mathrm{~N}$ ), the two curves were almost identical. It means that by the on/off control strategy, the damper reached its optimum effect with a voltage $125 \mathrm{~V}$ (the pressing force was $980 \mathrm{~N}$ ), above this value, the damping effect did not change. These results also agree well with the theoretical analysis in Section 2.

Figure 16 gives a comparison of the results of $A(1)$ with those of $\mathrm{A}(2)$. The amplitude-speed curves of $\mathrm{A}(1)$ were displayed by dotted line, while the results of $\mathrm{A}(2)$ by solid line. From Figure 16, it follows obviously that the on/off control strategy of the damper was sufficient to attenuate the vibration amplitude in the critical speed region.

Figure 17 shows the result of experiment $\mathrm{A}(3)$. It is the waveforms of vibration of the rotor system in horizontal direction at the rotational speed of $1524 \mathrm{rpm}$. The elastic support/dry friction damper was actuated at about $0.75 \mathrm{~s}$. The peak-to-peak value decreased rapidly from $400 \mu \mathrm{m}$ to $200 \mu \mathrm{m}$ approximately after $2 \sim 3$ periods (about $0.1 \mathrm{~s}$ ). Compared with Figure 9(b), the response time decreased more than $80 \%$. In Figure 9(b), the response time was $10 \sim 12$ periods (about $0.5 \mathrm{~s}$ ) [10].

Figure 18 illustrates the result of experiment $\mathrm{B}(1)$. It shows the waveforms of the rotor protected by elastic support/dry friction damper after blade-out event happened. The bladeout event happened at about the $51 \mathrm{~s}$, then the peak-topeak value increased rapidly and was maintained at about $260 \mu \mathrm{m}$. The elastic support/dry friction damper was actuated at about $56 \mathrm{~s}$ then the peak-to-peak value decreased and was maintained at about $200 \mu \mathrm{m}$. The result indicates that the protection effect by elastic support/dry friction damper is satisfactory.

Figure 19 shows the result of experiment $\mathrm{B}(2)$. It is the amplitude of rotor vibration in horizontal direction versus rotational speed during shut down when blade-out event happened. In Figure 19(a), firstly the rotor traversed the critical speed smoothly during startup in balanced state. Then at some time, the blade-out event happened. In this condition when the rotor shut down and coasted down the amplitude at the critical speed increased more than 2 times, from about $400 \mu \mathrm{m}$ to $1000 \mu \mathrm{m}$, this is extremely dangerous. In Figure 19(b), repeated the rotor startup process in the balanced state and blade-out event happened. After that,
TABLE 2: Comparison of two dampers.

\begin{tabular}{lcc}
\hline & $\begin{array}{c}\text { Electromagnetic } \\
\text { actuator }[8,10]\end{array}$ & $\begin{array}{c}\text { Piezoelectric ceramic } \\
\text { actuator }\end{array}$ \\
\hline Weight & $\begin{array}{c}7.4 \mathrm{~kg} \\
10 \sim 12 \text { periods } \\
\text { (about } 0.5 \mathrm{~s})\end{array}$ & $\begin{array}{c}3.5 \mathrm{~kg} \\
2 \sim 3 \text { periods } \\
\text { (about } 0.1 \mathrm{~s})\end{array}$ \\
Pesponse time & $25 \mathrm{~W}(\max )$ & $5 \mathrm{~W}(\max )$ \\
\hline
\end{tabular}

actuating the elastic support/dry friction damper (the control voltage was $100 \mathrm{~V}$, the pressing force was $810 \mathrm{~N}$ ). In this condition, the vibration of rotor system in the critical speed region was effectively controlled, and the rotor traversed the critical speed smoothly during shutdown. The peak amplitude almost equaled that in the balanced state.

In addition, the power of the piezoelectric ceramic was lower than $5 \mathrm{~W}$ in all the above experiments. Table 2 shows the comparison of important parameters of piezoelectric ceramic actuator and electromagnetic actuator. This comparison gives a clear result indicating the advantages of the elastic support/dry friction damper with piezoelectric ceramic actuator.

\section{Conclusions}

In this paper, an active elastic support/dry friction damper with piezoelectric ceramic actuator was designed, and its damping effectiveness on reducing vibrations of rotor systems was verified theoretically and experimentally. The main conclusions are summarized as follows.

(1) The elastic support/dry friction damper with piezoelectric ceramic actuator has good damping effects. The vibration amplitude of a rotor traversing the critical speed can be reduced significantly.

(2) For a designed rotor with the elastic support/dry friction damper, there is an optimum value of the pressing force between the stationary and moving disks at which the damper has the best damping effect. If the pressing force exceeds this value, the damping effect will become worse, and the characteristics of the rotor system will be changed.

(3) If the operating speed of a rotor is above the critical speed, the elastic support/dry friction damper with 
piezoelectric ceramic actuator can protect the rotor when a blade out event takes place. The damper can attenuate the vibration amplitude of the rotor traversing the critical speed significantly.

(4) The active elastic support/dry friction damper with piezoelectric ceramic actuator is featured by simple structure, light weight, fast response, and low power consumption. It is a promising active damper to be applied in rotating machinery.

\section{Conflict of Interests}

The authors declare that there is no conflict of interests regarding the publication of this paper.

\section{References}

[1] S. K. Sinha, "Rotordynamic analysis of asymmetric turbofan rotor due to fan blade-loss event with contact-impact rub loads," Journal of Sound and Vibration, vol. 332, no. 9, pp. 2253-2283, 2013.

[2] M. J. Stallone, V. Gallardo, A. F. Storace, L. J. Bach, G. Black, and E. F. Gaffney, "Blade loss transient dynamic analysis of turbomachinery," AIAA journal, vol. 21, no. 8, pp. 1134-1138, 1983.

[3] G. von Groll and D. J. Ewins, "On the dynamics of windmilling in aero-engines," in IMechE Conference Transactions, vol. 6, pp. 721-730, Professional Engineering Publishing, 2000.

[4] European Aviation Safety Agency, Certification Specifications for Large Aeroplanes CS-25, September 2008.

[5] F. Tianyu and L. Mingfu, "Dynamic behavior of a rotor with dry fricition dampers," Mechanical Science and Techonligy, vol. 22, no. 5, pp. 743-745, 2003.

[6] F. Tianyu, L. Mingfu, and W. Yankai, "Experimental investigation of dry fricition damper with elastic support," Mechanical Science and Technology, vol. 24, no. 9, pp. 1062-1065, 2005.

[7] F. Tianyu, Vibration Reduction by Elastic Support Dry Friction Damper, Northwestern Polytechnical University, Xian, China, 2006.

[8] W. Siji, M.-F. Liao, and S.-J. Yang, "Experimental investigation on rotor vibration control by elastic support/dry friction damper," Journal of Aerospace Power, vol. 22, no. 11, pp. 18931897, 2007.

[9] W. Siji and M.-F. Liao, "Control strategy and methods of rotor systems by an elastic support/dry friction damper," Journal of Aerospace Power, vol. 26, no. 10, pp. 2214-2219, 2011.

[10] W. Siji, Vibration Control Techniques for Rotor Systems by an Active Elastic Support/Dry Friction Damper, Northwestern Polytechnical University, Xi'an, China, 2008.

[11] W. Siji and L. Mingfu, "Online Control of rotor systems instability by elastic support/dry friction damper," Journal of Vibration Measurement \& Diagnosis, vol. 32, no. 2, pp. 323-327, 2012.

[12] A. B. Flatau and K. P. Chong, "Dynamic smart material and structural systems," Engineering Structures, vol. 24, no. 3, pp. 261-270, 2002.

[13] K. Sadeghipour, R. Salomon, and S. Neogi, "Development of a novel electrochemically active membrane and "smart" material based vibration sensor/damper," Smart Materials and Structures, vol. 1, no. 2, pp. 172-179, 1992.
[14] F. K. Straub, D. K. Kennedy, D. B. Domzalski et al., "Smart Material-actuated Rotor Technolnnogy-SMART," Journal of Intelligent Material Systems and Structures, vol. 15, no. 4, pp. 249-260, 2004.

[15] W. D. Iwan, The Dynamic Response of Bilinear Hysteretic Systems, California Institute of Technology, 1961.

[16] Z. Qingxing and M. G. Sainsbury, "The linearization of frictionally damped vibration system," Journal of Vibration and Shock, vol. 15, no. 4, pp. 249-260, 2004, vol. 6, no. 1, pp. 42-58, 1987. 

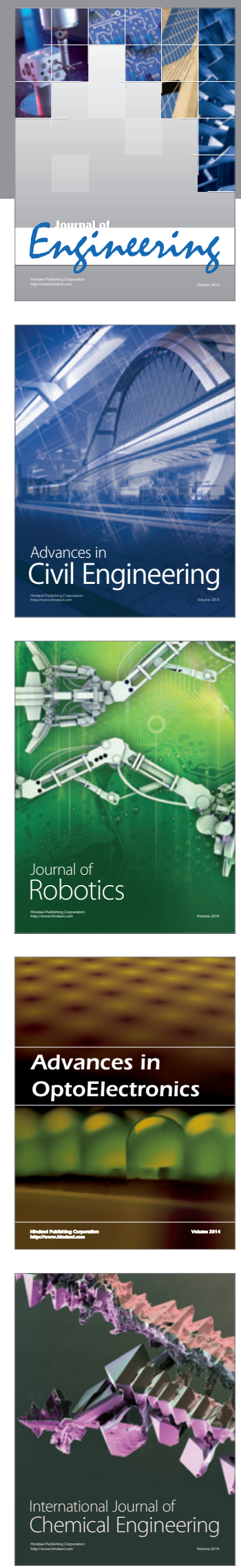

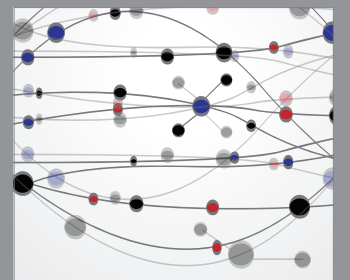

The Scientific World Journal
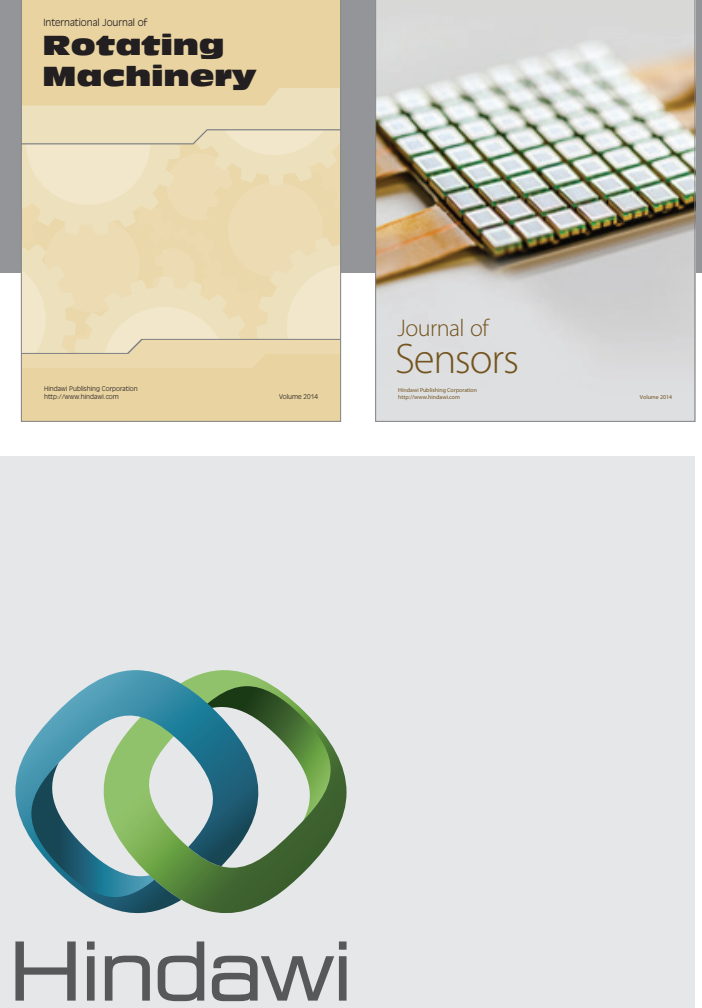

Submit your manuscripts at http://www.hindawi.com
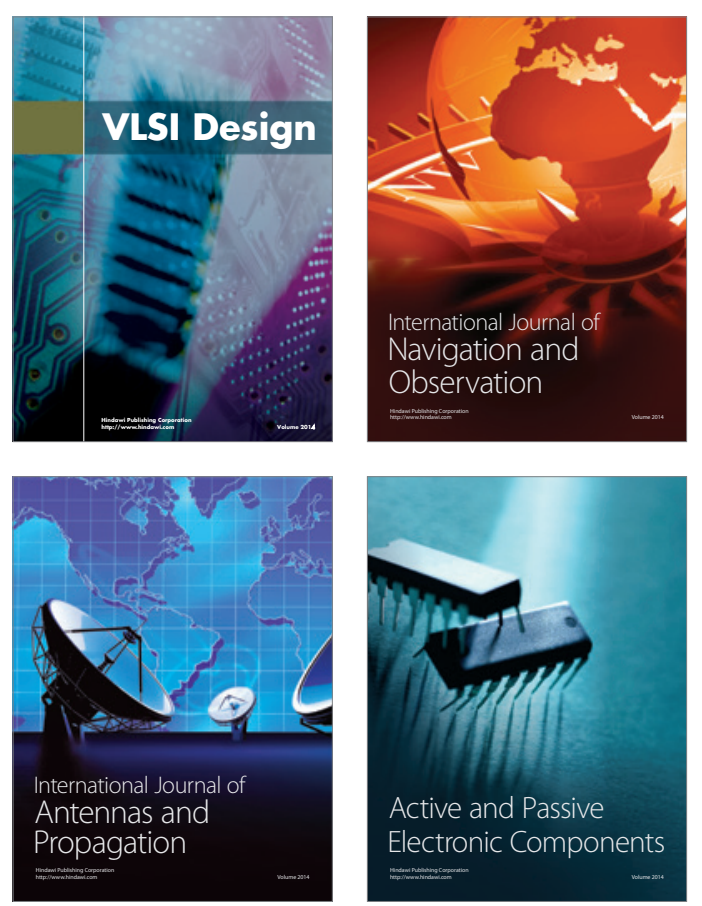
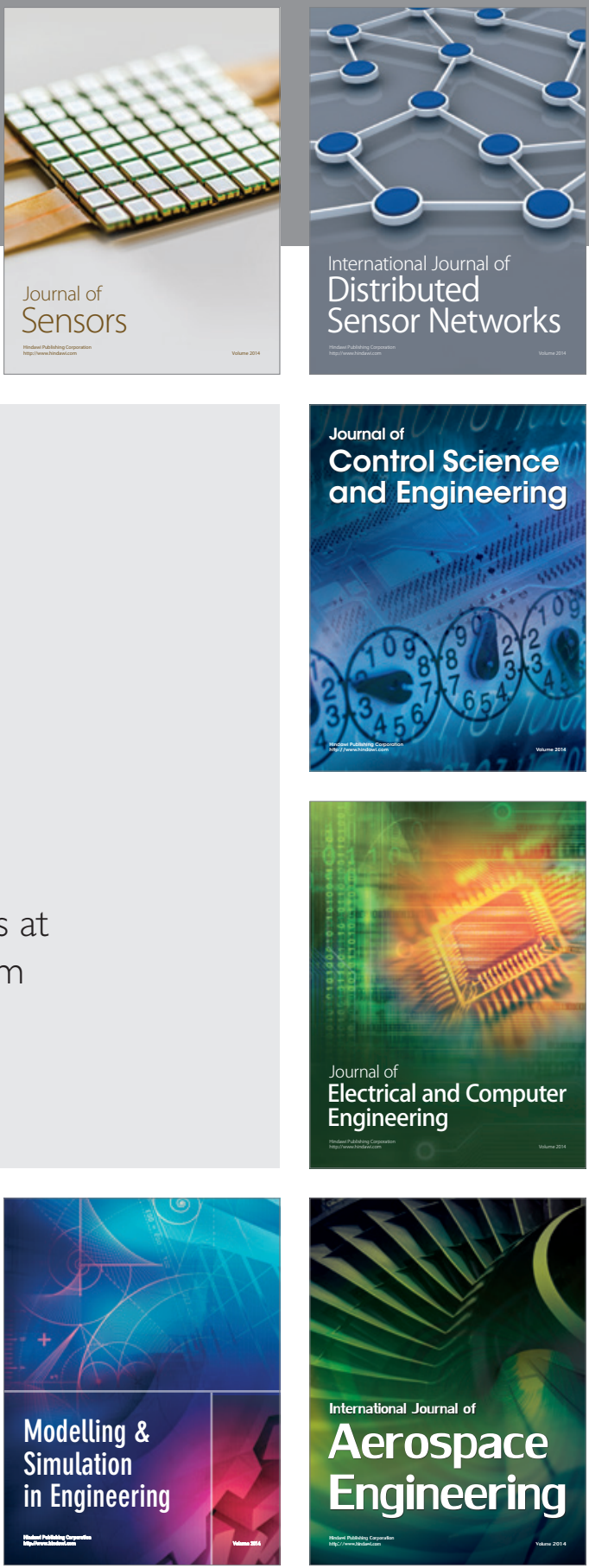

Journal of

Control Science

and Engineering
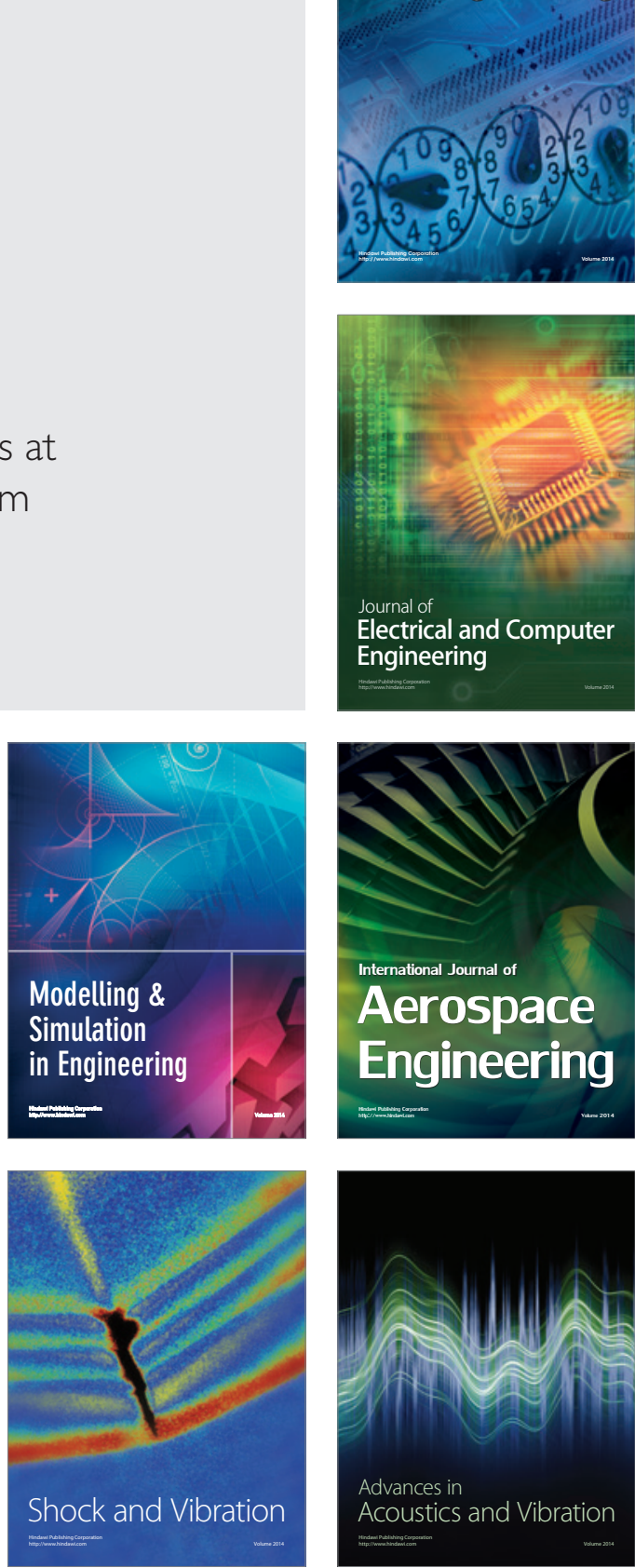